\section{Role of Combination Antibiogram in Empirical Treatment of Infection Due to Multidrug-Resistant Acinetobacter baumannii}

To the Editor-We read with interest the report by Mizuta and colleagues ${ }^{1}$ on the role of a combination antibiogram for empirical treatment of Pseudomonas aeruginosa infection. The emergence of multidrug-resistant (MDR) gramnegative microorganisms, especially Acinetobacter baumannii, has created prescribing dilemmas for physicians trying to select empirical therapy. ${ }^{2}$ In Thailand, the national incidence of MDR-A. baumannii-which is defined as A. baumannii that is resistant to 3 or more classes of antimicrobial agents-peaked at $45 \%$ in $2006 .^{3}$ Although dual therapy is commonly used when $P$. aeruginosa infection is suspected, most infectious diseases experts in Thailand also recommend dual therapy for suspected MDR-A. baumannii infections. Given reports that infections with MDR-A. baumannii were associated with higher mortality, ${ }^{4-5}$ one potential option is to use dual or triple empirical antimicrobial therapy. We, therefore, conducted a feasibility assessment to determine the optimal initial therapy for patients with MDR-A. baumannii infection.

We identified all hospitalized adults who had $A$. baumannii isolates recovered at Thammasat University Hospital from January 1, 2007, through December 31, 2007. If multiple $A$. baumannii isolates were obtained from the same patient during the same hospitalization, only the first isolate was evaluated. We used criteria suggested by the Clinical and Laboratory
Standards Institutes to identify A. baumannii and to establish antimicrobial susceptibility profiles. ${ }^{6}$ Antimicrobial susceptibility testing was performed with conventional susceptibility microbroth dilution trays, and we tested susceptibility for the following antimicrobials: gentamicin, amikacin, netilmicin, cefepime, ceftazidime, cefoperazone-sulbactam, ampicillin-sulbactam, ciprofloxacin, imipenem, meropenem, piperacillin-tazobactam, and colistin. We created a standard antibiogram for $A$. baumannii isolates, along with annual combination antibiograms created in a matrix fashion, which listed the antimicrobial agents tested both horizontally and vertically, as had been previously done by Mizuta and colleagues. ${ }^{1}$ In each matrix box of the combination antibiogram, we noted the percentage of isolates susceptible to at least 1 of the 2 agents (Table). The backbone of noncolistin-based, 2 -antibiotic regimens for triple antimicrobial agents was selected from the 2 antibiotics to which MDR-A. baumannii had the highest percentage of susceptibility: cefoperazone-sulbactam (32\%) and netilmicin (27\%).

There were $560 \mathrm{~A}$. baumannii isolates identified during the study period, of which $381(68 \%)$ were recovered from urine, 45 (8\%) from blood, and 134 (24\%) from other sites; 218 isolates (39\%) were MDR-A. baumannii. The majority of isolates (308 [55\%]) were recovered from intensive care unit patients. Antimicrobial susceptibility for A. baumannii as shown by the combination antibiogram (dual vs triple antibiotics) revealed that the combinations with the broadest coverage were consistently colistin-based regimens ( $100 \%)$, whereas cefoperazonesulbactam and netilmicin (54\%) provided the broadest coverage among noncolistin-based regimens (Table). Triple combinations of imipenem, cefoperazone-sulbactam, and

TA B LE. Combination Antibiogram for Acinetobacter baumannii, 2007

\begin{tabular}{|c|c|c|c|c|c|c|c|c|c|c|c|c|c|}
\hline \multirow[b]{2}{*}{ Drug } & \multicolumn{13}{|c|}{ Percentage of isolates susceptible to at least 1 of the 2 agents, by drug } \\
\hline & GEN & AMI & NET & CEFP & CETZ & $\mathrm{CP}-\mathrm{SB}$ & AM-SB & CIP & IMI & MER & PIP-TZ & $\mathrm{COL}$ & $\mathrm{CP}-\mathrm{SB}+\mathrm{NET}$ \\
\hline GEN & $\ldots$ & $\ldots$ & $\ldots$ & 28 & 21 & 39 & 34 & 21 & 31 & 30 & 36 & 100 & $\ldots$ \\
\hline NET & $\ldots$ & $\ldots$ & $\ldots$ & 31 & 34 & 54 & 39 & 31 & 40 & 39 & 35 & 100 & $\ldots$ \\
\hline CEFP & 28 & 30 & 31 & $\ldots$ & $\ldots$ & $\ldots$ & $\ldots$ & 25 & $\ldots$ & $\ldots$ & $\ldots$ & 100 & $\ldots$ \\
\hline CETZ & 21 & 23 & 34 & $\ldots$ & $\ldots$ & $\ldots$ & $\ldots$ & 20 & $\ldots$ & $\ldots$ & $\ldots$ & 100 & $\ldots$ \\
\hline AM-SB & 34 & 36 & 39 & $\ldots$ & $\ldots$ & $\ldots$ & $\ldots$ & 31 & $\ldots$ & $\ldots$ & $\ldots$ & 100 & $\ldots$ \\
\hline CIP & 21 & 24 & 31 & 25 & 20 & 35 & 31 & $\ldots$ & 29 & 30 & 24 & 100 & 49 \\
\hline IMI & 31 & 34 & 40 & $\ldots$ & $\ldots$ & $\ldots$ & $\ldots$ & 29 & $\ldots$ & $\ldots$ & $\ldots$ & 100 & 65 \\
\hline MER & 30 & 32 & 39 & $\ldots$ & $\ldots$ & $\ldots$ & $\ldots$ & 30 & $\ldots$ & $\ldots$ & $\ldots$ & 100 & 61 \\
\hline PIP-TZ & 36 & 35 & 35 & $\ldots$ & $\ldots$ & $\ldots$ & $\ldots$ & 24 & $\ldots$ & $\ldots$ & $\ldots$ & 100 & $\ldots$ \\
\hline $\mathrm{COL}$ & 100 & 100 & 100 & 100 & 100 & 100 & 100 & 100 & 100 & 100 & 100 & $\ldots$ & 100 \\
\hline
\end{tabular}

NOTE. A total of $560 \mathrm{~A}$. baumannii isolates were identified. The combination of the same antibiotic or $\beta$-lactam with $\beta$-lactam antibiotics were excluded from this analysis. AM-SB, ampicillin-sulbactam; AMI, amikacin; CEFP, cefepime; CETZ, ceftazidime; CIP, ciprofloxacin; COL, colistin; CP-SB, cefoperazonesulbactam; CP-SB + NET, cefoperazone-sulbactam and netilmicin; GEN, gentamicin; IMI, imipenem; MER, meropenem; NET, netilmicin; PIP-TZ, piperacillintazobactam. 
netilmicin increased the coverage to $65 \%$ among noncolistinbased regimens. Although colistin-based combinations provided the broadest coverage for infection with $A$. baumannii, colistin has recognized adverse effects and low tissue penetration in lower respiratory tract infections. ${ }^{7}$ The triple noncolistin-based regimens provided broader coverage than the dual noncolistin-based regimens for MDR-A. baumannii infections. These results were not substantially different when the analysis was repeated for the following subgroups: (1) isolates recovered from sites other than the urinary tract, (2) isolates recovered from the urinary tract, (3) isolates recovered from patients in the intensive care unit, and (4) isolates recovered from patients outside the intensive care unit.

Although antibiograms are often used by clinicians to assess local antimicrobial susceptibility rates, as an aid in selecting empirical antibiotic therapy, and in monitoring resistance trends over time in an institution, antibiograms do not reveal additional information concerning microbial isolates, such as the time the isolate was obtained relative to the time of the patient's hospital admission (to determine whether an infection was community acquired or healthcare acquired). In addition, an antibiogram cannot be used to select empirical therapy for a patient who develops an infection subsequent to a previous one, because a patient's particular infection history, including past antibiotic use, must be considered.

Limitations of our study include the restricted analysis of $A$. baumannii isolates, instead of an effort to empirically target a variety of gram-negative pathogens. Our findings would require modification if the process was repeated in other institutions, given the wide local and regional variations in antimicrobial susceptibility data. In addition, the ultimate choice of empirical antimicrobial regimen will also rest on other factors, such as suspected pathogens, likely site of infection, drug allergies and intolerance, drug penetration into different tissue sites, and drug toxicities. Nonetheless, the selection of empirical dual or triple combinations via antibiogram provides a useful tool to guide physicians in their initial decision making when MDR-A. baumannii infection is suspected in at-risk patients in endemic settings.

\section{ACKNOWLEDGMENTS}

Potential conflicts of interest. Both authors report no conflicts of interest relevant to this article.

Anucha Apisarnthanarak, MD; Linda M. Mundy, MD

Division of Infectious Diseases, Faculty of Medicine, Thammasat University Hospital, Pratumthani, Thailand (A.A.); St. Louis University School of Public Health, St. Louis, Missouri (L.M.M.).

Address reprint requests to Anucha Apisarnthanarak, MD, Division of Infectious Diseases Faculty of Medicine Thammasat University Hospital Pratumthani, Thailand, 12120 (anapisarn@yahoo.com).

Infect Control Hosp Epidemiol 2008; 29:678-679

(c) 2008 by The Society for Healthcare Epidemiology of America. All rights reserved. 0899-823X/2008/2907-0018\$15.00. DOI: $10.1086 / 588681$

\section{REFERENCES}

1. Mizuta M, Linkin DR, Nachamkin I, et al. Identification of optimal combinations for empirical dual antimicrobial therapy of Pseudomonas aeruginosa infection: potential role of a combination antibiogram. Infect Control Hosp Epidemiol 2006;27:413-415.

2. Abbo A, Navon-Venezia S, Hammer-Muntz O, Krichali T, Siegman-Igra Y, Carmeli Y. Multidrug-resistant Acinetobacter baumannii. Emerg Infect Dis 2005:11:22-29.

3. National Antimicrobial Resistant Surveillance Center. Annual epidemiology and surveillance report, 2007. Available at: http://narst.dmsc.moph.go.th/. Accessed January 1, 2008.

4. Abbo A, Carmeli Y, Navon-Venezia S, Siegman-Igra Y, Schwaber MJ. Impact of multi-drug-resistant Acinetobacter baumannii on clinical outcomes. Eur J Clin Microbiol Infect Dis 2007;26:793-800.

5. Lee NY, Lee HC, Ko NY, et al. Clinical and economic impact of multidrug resistance in nosocomial Acinetobacter baumannii bacteremia. Infect Control Hosp Epidemiol 2007;28:713-719.

6. National Committee for Clinical Laboratory Standards (NCCLS). Methods for dilution: antimicrobial susceptibility testing for bacteria that grow aerobically. 4 th ed. NCCLS document. Villanova, PA: NCCLS; 1997:M7-A3.

7. Falagas ME, Kasiakou SK. Colistin: the revival of polymyxins for the management of multidrug-resistant gram-negative bacterial infections. Clin Infect $D$ is 2005;40:1333-1341.

\section{Relationship Between Pathogenic and Colonizing Microorganisms Detected in Intensive Care Unit Patients and in Their Family Members and Visitors}

To the Editor-Recent data have demonstrated the usefulness of an unrestricted visiting policy in the intensive care unit (ICU), the so-called "open ICU."1-4 One of the most frequent objections to the open ICU, despite the lack of empirical evidence, is an increased risk of patient infection. ${ }^{2,3,5}$ It is generally argued that the transmission of microorganisms responsible for infections--so-called "cross-pollination" from visitors ${ }^{2}$ results from the presence of relatives in the ICU. Visitors and relatives also run the risk of acquiring infection. ${ }^{5}$

We designed a prospective, observational, pilot study to test the hypothesis that patients' family members are healthy carriers (reservoirs) of pathogens, which are, in turn, transmitted to patients, causing colonization or nosocomial infection. This study was conducted in an 8-bed, mixed medical-surgical ICU, with a nurse-to-patient ratio of $1: 2$. Patients in this ICU were treated in 1 room with 4 beds and in 2 rooms with 2 beds.

Family members ( 2 visitors per patient) were admitted in the afternoon from 12:30 pm-2:00 pm and from 6:30 pm-8:00 $\mathrm{pm}$. If the patient awakened or regained consciousness, the second afternoon visit can be extended from 4:00 pm-8:00 pm. For pediatric patients, an unrestricted visiting policy was applied.

The visitors were required to wash their hands and wear a disposable gown; shoe-covers, gloves, and masks were not required. Another hand washing was required on departure.

Using Margherita software (Istituto Mario Negri) ${ }^{6}$ we per- 